tion of a small portion of one potato as a treat two or three times a week. Her father being out of work, the family lived almost entirely upon bread, and the child had neither milk nor fresh meat. At the end of this time, the whooping-cough being severe, and the purpura having appeared, the mother transferred the child to this hospital, where she attended as an out-patient. The paroxyms of cough, which were of excessive violence, abated in the most striking manner under the use of tincture of Indian hemp, a remedy which, when given in full doses and carefully mixed with mucilage to prevent precipitation, is in my experience the most valuable of all the sedatives in the later stages of this disease. The purpura did not, however, disappear pari passu, in spite of the full diet and fresh vegetables which were directed to be given. Fresh crops of ecchymoses appeared from time to time. It is probable that the impoverished circumstances of the family did not permit them to feed the child properly. Two lemons were now ordered to be taken daily, and from that time the purpura faded away, and no fresh blotches have appeared for several weeks. The girl is, as you see, nearly well, and as the whooping-cough has gone, she has been received into this hospital in order to be transferred to the convalescent branch at Highgate, where the cure will be confirmed by wholesome country air.

The truth, then, with regard to these two affections, scurvy and purpura, appears to be this. Purpura is not to be regarded as a distinct disease, but as a symptom denoting a certain condition of blood and blood-vessels which occurs in several distinct diseases. The most common disease of which purpura is one of the phenomena is scurvy and I believe that the majority of cases of so-called purpura met with in this country are cases of slight or imperfectly developed scorbutus. And this view is confirmed by the fact that we meet with every gradation of the disease, from a few scattered ecchymoses to the extensive extravasations, indurations, ulcerations, and serous inflammations of its full development. All degrees arise, as a rule, under similar conditions of life-viz., scanty unvaried diet, such as the bread and weak tea which form the staple food of the London poor, foul dwellings, or lack of fresh vegetables. When these evil conditions, and especially the latter, are present in moderate degree, so-called purpura results; when they are present to an extreme degree, or their action greatly prolonged, the extreme form of the disease is produced, and so-called scurvy follows; and, lastly, the disease may arise, as in two of the cases I have shown to you, when no defect of diet or any hygienic condition can be traced, and in which the blood-fault must be due to some secret cause which has not yet been fathomed.

\section{CASE OF PULMONARY HÆMORRHAGE.}

\section{By W. J. BARKAS, L.R.C.P.Lond,, M.R.C.S.Eng., Newcastle-on-Tyne.}

THE following case came under my notice while acting as surgeon in the steamship Emblchope, on her return voyage to England from Calcutta. It is mainly curious from the large amount of blood the man lost during the last ten days of his life. He had from one to three attacks of hæmorrhage every day, the quantity varying from one and a half gills to rather more than a quart. During his recovery from the slight pneumonic attack, the pulse gradually became slower, though the temperature remained very high. The ship was for some time in very rough seas, and in a disabled,state from the engines breaking down and the hold filling with water. The waves kept washing over her decks, thus causing the sailors to be constantly at work at the pumps, while their clothes were saturated with water; and, with their usual recklessness, they would actually lie down to sleep in that condition.

The patient was J. G., aged 38 , a seaman, married, and having two children. He had undergone great hardships from shipwreck and other casualties, and had led a very laborious life-so much so that he had the appearance of a man of 50 years, though he had been all his life a careful and temperate person, and had never suffered from any severe illness. On the voyage from England he had a slight attack of bronchitis, which left an occasional short hacking cough, without any expectoration, and without any difficulty of breathing. From that time till this illness came on he felt perfectly well, with the above exception. During the afternoon of June 2 Ist, I872, he was seized with a violent fit of coughing, followed by a copious flow of red fluid blood, which coagulated into a firm clot immediately on exposure to the air. The bleeding soon ceased. On seeing him again two hours afterwards, he was expectorating blood mixed with a little mucus; the cough was very slight, with no difficulty of breathing; pulse 82 ; tongue clean ; skin moist and warm ; bowels open. There was slight dulness on percussion, and some small crepitation at the posterior portion of the base of the right lung. The heart's action was feeble, but normal. On the 22nd ( 7 A.M. $)$, he had passed a quiet night; he expectorated some pure blood, but the sputa were commencing to assume the rusty colour of pneumonia. His cough was very slight; pulse 100 ; temperature Iol deg.; no pain. He was treated by ammonia, plenty of nourishment and port wine, and by the constant application of hot poultices over the chest. At 4 P.M., there was no increase of dulness; temperature 103 deg. Shortly after this visit, he had a severe fainting fit, but soon recovered, with only a slight headache, which was relieved by cold applications. On the 23 rd, dulness on percussion was still present; he had very little cough or expectoration; pulse IOO; temperature $102 \mathrm{deg}$. On the $24^{\text {th }}$, the sputa were bloody ; pulse 90 ; temperature 103 deg. He was ordered ten grains of quinine night and morning. On the 27 th, the temperature had fallen to Ioo deg.: the quinine was continued, and he was ordered to have quinine mixture three times a day. On the 28 th, the lungs were free from dulness ; he had no cough or expectoration ; pulse 80 ; temperature 98 deg. From this date he rapidly improved, and was gradually able to resume work; but on July 7 th, alarming pulmonary hæmorrhage occurred without any previous warning. He appeared in his usual health even after the attack was over. There were no signs of phthisis, aneurism, congestion of lungs, or heart-disease. Mr. Lee, Resident Civil Surgeon, Trincomalee, saw the case with me, and was also unable to detect any cause for the hæmorrhage. I ordered him a mixture containing dilute sulphuric acid and sulphate of magnesia. On July 8th, he had had a return of the hæmorrhage, but expectorated bloody mucus. He was ordered to take 30 minims of tincture of sesquichloride of iron every four hours. On the IIth, he had had three or four attacks of bleeding. since the 8th. The quantity of blood lost in each bleeding varied from. a pint to a quart. He was ordered to take the tincture every two hours. There was no hæmorrhage until the 17 th, when it broke out to a more alarming extent than before. I now gave gallic acid in twentygrain doses, but without effect. On the Igth, I ordered him to take fifteen minims of oil of turpentine every ten minutes during the attacks, and every hour between them. This seemed to lessen the quantity of blood lost, but did not prevent the bleedings from returning. The debility rapidly increased, and the breathing was very difficult during the attacks, but not at other times, he only then feeling languid and weak. This continued till the 27 th, when he died from asphyxia, not being able to cough up the blood, which was flowing in large quantity. I was not able to obtain a post mortem examination.

\section{PARACENTESIS THORACIS.*}

By W. A. I'ANSON, Esq., M.R.C.S., L.R.C.P.Ed., Honorary Surgeon to the Prudhoe Memorial Convalescent Home, Whitley.

JAMES O, aged Io, complained of chilliness and lassitude on February Ist. During the night fever set in, accompanied with delirium and a lancinating pain in the right side. On the following day, and up to March Ist, when first seen, he had been playing about the house, although he was during each night feverish, and slightly delirious, and occasionally referred to pain in the right side.

On examination, the skin was found to be hot and dry ; the respira. tion somewhat increased in frequency, with short troublesome cough; there was also pain in the right side, inability to lie on the left side, etc. On listening to the right chest, no sound of any kind was heard except that produced by the air passing into the larger bronchial tubes; the respiration on the left side was puerile. $\mathrm{He}$ was ordered diaphoretic medicines, etc.

March 2.-During the evening the skin became moist; and through the night free perspiration set in.

March 3. 9 A.M. - The boy suffered from urgent dyspncea, and had to get the head raised. Bronchial respiration was quite gone; the right side was stationary during respiration; there was a complete dulness on percussion at the back as high as the spine of the scapula; also total absence of vocal fremitus and vocal resonance. His face was pinched and dusky-looking; pulse I 30 . Throughout the afternoon the dyspnœea was of a suffocative character, with a sense of great pressure in the neck near the right sterno-clavicular articulation. The signs of suffocation were so well marked that the parents watched over him, expecting every minute to be his last. He was again seen at 5.30 P.M., and the operation of tapping the chest was advised, as the only means likely to save his life. At my request, Dr. Philipson kindly met me in consultation, and fully coincided with the diagnosis, and necessity for immediate operative measures. The trocar and cannula (a long vulcanised Indiarubber tube being attached to the cannula, with the free end in a basin

Read before the Northern Branch. 